\title{
Paula Cesarino Costa: os desafios da ombudsman da Folha de S. Paulo entre 2016 e 2019
}

Elaine JAVORSKI ${ }^{1}$

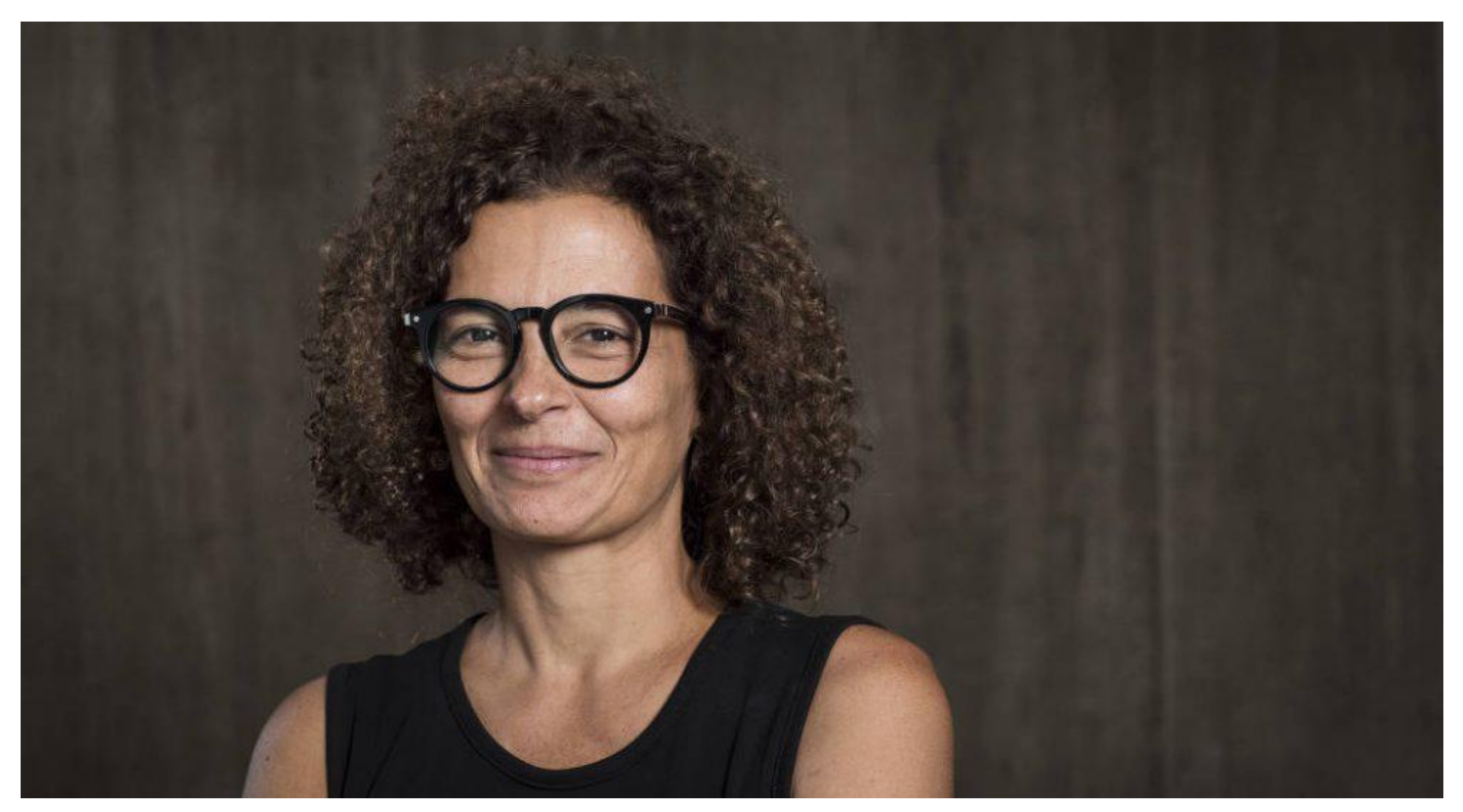

Fotografia de Eduardo Knapp/Folhapress

A Folha de S. Paulo foi o jornal pioneiro na implantação do cargo de ombudsman no jornalismo brasileiro em 1989. Poucos foram os periódicos que tiveram a iniciativa de ter na sua redação alguém que realizasse a autocrítica. Em 2002, dos 371 jornais diários que circulavam no Brasil apenas seis contavam com ombudsman (CARRATO, 2002). É provável que esse tenha sido o período com o maior número de jornalistas ocupando essa função no país. Atualmente, dos mais de quatro mil jornais em circulação, conforme dados da Associação Nacional dos Jornais (ANJ), somente dois mantêm a função com colunas fixas semanais: a Folha de S. Paulo e o jornal O Povo, do Ceará.

\footnotetext{
1 Doutora em Ciências da Comunicação e dos Media pela Universidade de Coimbra. Professora adjunta da Faculdade de Comunicação na Universidade Federal do Sul e Sudeste do Pará. E-mail: elaine.javorski@unifesspa.edu.br
} 
Desde a criação da coluna na Folha, já passaram pelo cargo 13 jornalistas. Paula Cesarino Costa foi a $12^{\mathrm{a}}$ defensora dos leitores da Folha e quinta mulher a ocupar a função, entre 25 de abril de 2016 e 4 de maio de 2019. Formada em Jornalismo pela Pontifícia Universidade Católica de São Paulo, com pós-graduação em Cinema Documentário pela Fundação Getúlio Vargas, do Rio de Janeiro, é funcionária da empresa desde 1987 e ocupou a direção da Sucursal do Rio por 12 anos, desde 2004. Antes disso foi secretária de Redação, onde desempenhou diferentes funções: editora de Política, editora de Especiais, editora de Negócios e editora de Treinamento, tendo começado como redatora do extinto caderno cultural Folhetim. Depois do trabalho como ombudsman, Paula assumiu a editoria de Diversidade. Na entrevista apresentada a seguir, ela fala dessa experiência e da importância da autocrítica para o jornalismo.

No período em que você ocupou o cargo de ombudsman, entre abril de 2016 e maio de 2019, acontecimentos importantes mudaram o rumo da história política do Brasil. Esses eventos, aliados à facilidade de difusão de informação e opinião pelas redes sociais e aplicativos de mensagens instantâneas, deixaram bastante evidente a polarização que ultrapassou as questões políticas no país. Como você avalia esse período?

Paula Cesarino Costa: Foi um período muito rico em termos de notícias e um momento no qual as fake news passaram, de fato, a ser uma realidade com a qual o jornalismo precisava lidar. Além de tudo, foi um período de agravamento da crise do modelo de negócio da imprensa, que ainda continua. Os jornais foram muito desafiados e é nessa hora que mostra-se importante o trabalho do ombudsman. Eu acho que consegui, tanto nas críticas internas do jornal como nas colunas publicadas aos domingos, colaborar para que o jornal conseguisse realizar discussões internas e também influenciar um pouco na produção do jornal diário. Levantei discussões importantes e trouxe preocupações com alguns ajustes que a Folha poderia fazer. Para mim, pessoalmente, foi muito importante e, para a função do ombudsman em si, acho que foi um período de fortalecimento da importância de se ter essa figura nos tempos atuais. 
Você tratou de questões relacionadas às notícias falsas em algumas das suas colunas. Dentre elas, "Zap-zap da notícia falsa", de 8 de julho de 2018, citou o caso do crescimento da divulgação de fake news nas eleições do México, e em "Perigosas armadilhas virtuais", de 3 de dezembro de 2017, faz um alerta sobre os riscos do consumo virtual de informações e o desafio que enfrenta o jornalismo. Essa é a maior preocupação hoje do jornalismo?

Paula Cesarino Costa: As pessoas falam muito sobre as fake news, mas esse fenômeno é apenas um detalhe de um processo ainda maior. Esse não é o único assunto e nem a única preocupação do jornalismo. Acho que a principal prioridade é a de manter a relevância do jornal pela qualidade jornalística, justamente para conseguir, em tempos tão polarizados, trazer todos os lados de cada uma das histórias. Não são apenas dois lados, são vários. Então é preciso ter essa preocupação centrada na questão da credibilidade que o veículo deve ter.

E como se constrói essa credibilidade em tempos de compartilhamento acelerado de informações?

Paula Cesarino Costa: Eu acho que a transparência é fundamental, no sentido amplo, tanto sobre como as decisões são tomadas, a capacidade de reconhecer e apontar os próprios erros, e também ficar alerta com as questões que cada vez mais se misturam: o noticiário e as condições para o jornal se manter, do ponto de vista financeiro. Essas decisões não podem influenciar o noticiário. É importante o jornal dizer que tem o apoio de determinados anunciantes para que o leitor tenha ciência da independência. Transparência é o segredo da credibilidade. Além disso, é preciso buscar as várias versões, várias abordagens dos assuntos, que são os elementos decisivos para manter a credibilidade. Quando o jornalista analisa só um lado, principalmente em tempos de polarização, facilmente pode cair numa campanha, numa postura que só vê um lado da história. Isso é perigoso. De uma certa forma, o atual governo favorece a credibilidade dos veículos porque ele deu chance aos jornais de mostrarem sua necessidade, sua importância e também a sua credibilidade. 
Você acompanha os comentários das redes sociais? Parece que muitos(as) leitores(as) andam desconfiados(as) do jornalismo ou só acreditam naquilo que confirma seu ponto de vista. Isso é mais visível com o material opinativo ou informativo?

Paula Cesarino Costa: Eu acompanho pouco as redes sociais, mas é fundamental olhar o que está sendo falado. Tem que se olhar criticamente porque é muito fácil você identificar os leitores que têm lado. Então é preciso diferenciar aqueles que são críticos daqueles que estão apenas torcendo. É preciso olhar isso criticamente mas o jornal não pode se orientar a partir das redes sociais. A preocupação do jornal em termos de credibilidade é especialmente na questão do noticiário, do jornalismo informativo, que é o coração do jornal e mostra se o jornal tem relevância, se é sério. A Folha tem uma política de ter colunistas dos mais diversos pensamentos. Então vai existir sempre o colunista que algumas pessoas odeiam e outras amam. Como ombudsman eu via isso todo dia. Haviam leitores obcecados por alguns colunistas e que falariam mal dele independente da posição que ele demonstrasse ter sobre determinado assunto. A ideia da diversidade e da pluralidade de colunistas é que você tenha as mais diferentes posições e opiniões. Mas o jornal deve assumir também que a escolha dos colunistas faz parte da postura editorial. Então acho que existiram momentos, não na minha gestão mas na anterior, em que o jornal levou para suas páginas um pouco da radicalidade que aparecia muito no Facebook, na época. Eram colunistas radicais em posições muito opostas, mas que não tinham, necessariamente, qualidade de argumentação. É importante ter várias visões, diversas e contraditórias, mas o jornal precisa ter a responsabilidade de escolher colunistas que de fato tenham coisas a dizer. Isso é fundamental. Não adianta somente colocar o colunista que é sucesso na internet e ganha cliques.

No livro “Ombudsman - O Relógio de Pascal”, Caio Túlio Costa, primeiro ombudsman da Folha, fala do conflito que teve com o colunista no jornal na época, Paulo Francis. Lidar com as polêmicas que os articulistas do jornal causam parece uma das tarefas mais ardilosas para o ombudsman, já que seu papel está mais centrado na crítica do material informativo, como você disse. Você fala um pouco 
dessa relação na coluna "Aos leitores, gratidão", de 25 de dezembro de 2016. Outro texto que trata do assunto foi "Direito de criticar e de reclamar", de 16 de outubro de 2016, quando um artigo sobre a Lava Jato, do professor universitário Rogério Cezar de Cerqueira Leite, membro do Conselho Editorial da Folha, gerou uma carta de protesto do então juiz Sérgio Moro. Na mesma coluna você explicou o caso de uma charge de André Dhamer que foi considerada ofensiva pelos(as) leitores(as). Como se dá essa relação com colunistas que, como você cita em uma coluna, chegam ao número de 130 na versão digital?

Paula Cesarino Costa: Assim como Caio Tulio Costa, eu também não me debruçava sobre isso. Uma ou outra coluna pode ter tido algum tipo de problema mas considero que o colunista não é objeto de análise do ombudsman. Comentar opinião não tem muito sentido. Mas quando uma opinião mobiliza os leitores de uma forma excepcional, acho que, como o ombudsman é o representante do leitor, é preciso comentar de alguma forma. Mas não é caso de fazer uma análise sobre a opinião do colunista e sim comentar sobre a reação que a coluna desencadeou.

Como era a participação do(a) leitor(a)? Ele(a) conversava com você por meio de quais canais?

Paula Cesarino Costa: A participação do leitor é intensa. A questão dos canais pelos quais conversam com o ombudsman é uma coisa que está muito em mudança. No início, os relatos dos ombudsmans mais antigos mostram que as manifestações eram basicamente por carta e por telefone. Os primeiros ombudsmans ficavam horas com o leitor ao telefone. Depois, o contato passou a ser essencialmente por e-mail e apenas um ou outro telefonava. Hoje nós temos aquele leitor muito participativo, principalmente os leitores mais antigos e mais fiéis ao jornal, aqueles que estão lendo a Folha sempre. Eles continuam mandando e-mail e são fundamentais para o ombudsman ter ideia da audiência. Mas ele é apenas uma parcela do leitor da Folha. Em momentos de temas de maior repercussão ou mais polêmicos você recebe uma onda de leitores mais partidários, digamos assim, às vezes até combinados. Um dia teve uma matéria sobre um seminário sobre ateísmo. Recebemos uma enxurrada de e-mails de pessoas contra a questão do 
ateísmo. Então alguns temas acabam movimentando discussões específicas. Acho que o desafio hoje do ombudsman é você buscar o leitor que deixou de estar só no e-mail e está nas redes sociais. Quando a Folha fechou os comentários só para assinantes no site foi muito importante, porque qualificou os comentários. Não havia mais o anônimo que falava um monte de barbaridades. A partir de então o comentário era feito pelo sujeito que tem nome e sobrenome e responsabilidade pela sua opinião. O ombudsman tem, portanto, que estar atento aos comentários que são feitos nas matérias no site. $\mathrm{O}$ ombudsman tem que ir no Twitter, no Facebook, no Instagram, mas ter uma percepção afinada sobre quem é esse leitor exatamente. Muitos dos que comentam a Folha nas redes sociais não leem a Folha. São pessoas que comentam muitas vezes sem ter lido o conteúdo completo da matéria. Uma das dificuldades hoje do ombusman, então, é repensar essa relação com o leitor, como estar mais próximo dele e como conseguir saber o que ele de fato está achando da cobertura.

\section{E qual o perfil do(a) leitor(a) que utiliza o ombudsman para expressar opinião sobre} o jornal? Ele(a) escreve mais para reclamar ou para tirar dúvidas, elogiar?

Paula Cesarino Costa: Nós temos uma estatística sobre isso. Cerca de $80 \%$ dos leitores que escrevem fazem algum tipo de reclamação. Homens comentam mais do que mulheres e a editoria que mais recebeu comentários no período em que eu estive no cargo foi Política, até porque foi um momento especialmente movimentado do ponto de vista político. Eu peguei o impeachment da então presidente Dilma, uma eleição e a prisão do ex-presidente Lula. Foi um momento em que a questão política passou a ser de interesse de todas as pessoas, mesmo aqueles que não acompanhavam passaram a comentar. Para além da política, também percebemos que os colunistas, de forma geral, mobilizam muito os leitores.

Desses momentos turbulentos que você viveu como ombudsman, qual foi o mais complicado?

Paula Cesarino Costa: Como eu peguei o impeachment da Dilma e as eleições de 2018, é difícil saber qual foi o período de maior polarização. A eleição culminou em um período 
todo de polarização, então o desafio do jornal era manter o equilíbrio. Acho que em alguns momentos isso não foi alcançado porque se valorizou demais algumas questões do Bolsonaro, por exemplo, mas de uma forma geral eu acho que o jornal foi bem. Conseguiu ser crítico um pouco dos dois lados. O país se dividiu muito e a Folha perdeu leitores, de fato, primeiro à esquerda, depois à direita, e mais tarde recuperou os eleitores à esquerda. Mas isso faz parte desses momentos políticos em que as pessoas não têm nenhuma objetividade. A versão delas é mais sentimental do que racional.

Em algumas colunas você chegou a falar sobre questões de liberdade de imprensa, como no artigo "A imprensa na berlinda", em 19 de agosto de 2018, exemplificando a ameaça a jornalistas feita constantemente pelo governo de Trump, nos Estados Unidos. No dia 4 de novembro de 2018, em "O presidente contra a imprensa", e também na coluna de 31 de março de 2019, em "O presidente e a fonte do mal", você comenta o relacionamento complicado do presidente Jair Bolsonaro com a imprensa e principalmente com a Folha. Como você analisa essas situações?

Paula Cesarino Costa: Eu acho que não é possível dizer que existe uma ameaça à liberdade de imprensa. O que há, de fato, são provocações. O que é mais preocupante hoje são as ameaças legais como, por exemplo, o que aconteceu com a Elvira Lobato no caso da Igreja Universal ${ }^{2}$. Existem tentativas de dificultar o trabalho da imprensa e impedir a liberdade de imprensa com algumas decisões judiciais controversas. Isso é preocupante. Mas isso se enfrenta com o bom jornalismo. Se mantivermos credibilidade, equilíbrio e reportagens com qualidade é mais difícil que se consiga impedir a liberdade de imprensa. Claro que o cenário é muito preocupante porque você tem, aliado a isso, uma crise no setor do ponto de vista financeiro. As empresas estão cortando custos, cortando pessoal, não conseguem investir em tecnologia como é fundamental fazer, então é preciso tentar se reinventar. As empresas e o próprio jornalismo precisam, de forma geral, se reafirmar como relevantes. Jornalismo, mais do que nunca, precisa mostrar sua relevância, ainda mais em momentos muito confusos como esse que vivemos.

\footnotetext{
2 Reportagem publicada em 2007 com importantes repercussões.
} 
O ombudsman também costuma dar espaço para os(as) jornalistas da redação. Nas suas colunas eles(as) foram entrevistados algumas vezes, como foi o caso da Maria Cristina Frias, que assumiu a direção de Redação, na coluna de 10 de março de 2019 e, pouco depois, com a saída dela, Sérgio D’Ávila, recém nomeado para substituí-la, foi entrevistado para a coluna de 24 de março de 2019. Além disso, você trouxe relatos dos(as) repórteres da Folha sobre a profissão, o que mostrou um pouco dos bastidores do jornalismo. É importante mostrar o cotidiano do jornalismo?

Paula Cesarino Costa: O leitor pede muito. O ombudsman faz uma mediação entre o leitor e a redação. Então o leitor quer saber o que o jornalista acha, quer entender as decisões da redação. Não interessa que o ombudsman dê somente sua opinião, faça sua crítica técnica ou não, mas que explique o que motivou o jornal. Nesse sentido o ombudsman tem a obrigação de comentar as decisões, dizer se concorda ou não, se acha que foi ou não correta. Eu acho fundamental que a coluna abra esse espaço. Não deve usar o espaço para publicar release da direção mas cada análise que faz, e não é sempre, é importante. Várias vezes a explicação dada pelo jornal era criticada pelo leitor no dia seguinte. Isso é uma das essências da transparência.

Em muitas colunas você faz comentários elogiosos ao temas que considera bem trabalhados. No dia 2 de setembro de 2018, a coluna "Boa jogada", por exemplo, tratou do sucesso da plataforma da Folha que ajudava a escolher o deputado. Também de crítica construtiva vive o ombudsman, não é?

Paula Cesarino Costa: Mostrar o que está certo é importante. Não é sempre que o ombudsman faz isso. Para que aconteça, o acerto do jornal deve ser algo realmente muito bem feito, muito consistente, para que sirva de exemplo. Eu fiz algumas colunas elogiosas de forma a mostrar aos jornalistas da própria empresa, e também ao leitor, que existe um jornalismo bem feito. Educar o leitor a ler o jornal mas não de maneira prepotente. Elogio é bom, mas no fundo o que importa é saber sobre o que desagrada o leitor. 


\section{Nessa transição entre o impresso e o digital, quem é o(a) leitor(a)?}

Paula Cesarino Costa: Isso tem mudado muito rapidamente. Existem cada vez mais leitores que eram do impresso e que passaram a ser do digital. Na crítica interna, na qual sempre entrevistamos um leitor, quando perguntamos como lê a Folha ele diz que já lê o digital ou lê as duas versões. Você vê claramente que só os leitores mais velhos leem só o impresso.

\section{Você falou sobre a crítica interna. Como ela é feita? Como é dado o retorno aos(às) jornalistas da redação?}

Paula Cesarino Costa: Existe uma crítica que circula internamente na redação, diária, com a avaliação do jornal do dia e uma comparação com outros jornais. Essa crítica vem acompanhada, já desde quando Suzana Singer ocupava o cargo, de uma entrevista feita com um leitor. Ele é escolhido de forma variada e aleatória. Às vezes a gente o encontra na lista de assinantes ou às vezes selecionamos alguém que escreveu alguma coisa interessante e nos mandou. Eventualmente também personalidades, pessoas mais conhecidas. Tem-se ali, sob a vinheta "Sua Excelência, o Leitor", a opinião de leitores comuns sobre assuntos diversos. O retorno aos jornalistas é feito através do Blog do Ombudsman, onde há a possibilidade deles se manifestarem, contestarem, ponderarem, criticarem. O ombudsman responde ou não, conforme a necessidade.

Voltando ao tema do impresso versus o digital, como você acha que será dentro de alguns anos? Quando um(a) historiador(a) precisar compreender o que aconteceu no passado, qual recurso será que ele(a) vai ter para pesquisa?

Paula Cesarino Costa: É difícil prever o futuro do impresso, se ele vai acabar, qual será a importância dele. Se ele continuar, será menor. Mas o grau de relevância, não sei dizer. Hoje o impresso ainda tem mais relevância, ainda tem maior credibilidade. Isso vem mudando muito rapidamente. Isso vai facilitar e dificultar a vida dos historiadores porque ao analisar o impresso você consegue observar o que o jornal valorizou como importante. No formato limitado do impresso estão muito claras as escolhas da manchete, do conteúdo. Por outro lado, no digital vai ser possível encontrar uma quantidade maior de 
informações, de se retratar a época. Isso está muito em movimento. Claramente o jornal digital vai ser importante: no celular, no computador. Mas para isso todos os jornais brasileiros precisam melhorar suas versões digitais, o que requer investimento em tecnologia.

Nesse período em que ocupou o cargo você chegou a ter contato com outros(as) ombudsmans?

Paula Cesarino Costa: Antes de assumir eu estive no New York Times com a Margaret Sullivan, que era a representante dos leitores (public editor) há quase quatro anos. Ela me orientou para pensar como eu deveria agir como ombudsman. Fiz uma breve entrevista que publiquei na coluna "Trazer o leitor para dentro da notícia", em 1 de maio de 2016. Depois ela deixou o cargo e foi para o Washington Post. É atualmente uma das principais críticas de mídia que existem. Também estive em contato com os ombudsmans do El País (Espanha), The Guardian (Inglaterra) e participei de uma reunião da associação internacional dos ombudsmans de mídia, na Índia. Conheci o jornal The Hindu e foi muito interessante a experiência. Infelizmente, a cada ano que passa é menor o número de ombudsmans de jornal, principalmente de empresas privadas. Existem muitos críticos de veículos de comunicação pública, de órgãos estatais, como a televisão pública da Dinamarca e do Canadá, por exemplo.

Uma das características que parece mais importante para que um(a) jornalista ocupe o cargo de ombudsman é a experiência. É verdade?

Paula Cesarino Costa: Eu tenho 32 anos de Folha. Mas o ombudsman pode ter perfis muito variados. É importante a experiência, um discernimento crítico, ter equilíbrio com curiosidade de ouvir todos os lados. Sobretudo é preciso ter esse olhar para os erros dos outros, precisa ter humildade para ler o jornal e se colocar na posição do leitor e também na posição da redação. É a experiência que faz com que você consiga transitar nesses dois lados. Eu acho também importante ter um espírito de mediação, compreender que não é um "sabe-tudo". O ombudsman não é superior aos outros jornalistas. Ele está ali para ouvir os leitores, fazer uma análise a partir da sua capacidade técnica, mas a opinião dele 
não é absoluta. Na entrevista com a Margaret Sullivan ela me disse uma coisa importante: o segredo é o tom que você tem e que você coloca nas críticas que você faz. Quando você vai pela ironia é sempre problemático porque cada pessoa entende de uma forma. Agressividade também não é o caminho. O ideal é ter um tom equilibrado, respeitoso e até de bom humor com o colega jornalista.

\section{Referências}

CARRATO, Ângela. Jornais, ombudsman e cidadania: um balanço (provisório) dos últimos 10 anos no Brasil. In: CONGRESSO BRASILEIRO DE CIENCIAS DA COMUNICAÇÃO, 25., 2002, Salvador. Anais [...] São Paulo: INTERCOM, 2002. Disponível em http://www.intercom.org.br/papers/nacionais/2002/Congresso2002_Anais/2002_NP2C ARRATO.pdf. Acesso em: 12 jun. 2020.

COSTA, Caio Túlio. Ombudsman - o relógio de Pascal: a experiência do primeiro ombudsman da imprensa brasileira. São Paulo: Editora Geração, 2006.

Submetido em: 30.10.2019

Aprovado em: 30.03 .2020 